\title{
ELECTROMYOGRAPHY AND INSTRUMENTATION IN PATIENTS WITH IDIOPATHIC SCOLIOSIS
}

\author{
ELETROMIOGRAFIA E INSTRUMENTAÇÃO EM PACIENTES COM ESCOLIOSE IDIOPÁTICA
}

ELECTROMIOGRAFÍA E INSTRUMENTACIÓN EN PACIENTES CON ESCOLIOSIS IDIOPÁTICA

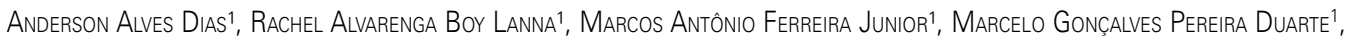

Roberto Sakamoto Falcon'1, Manuel de Araújo Porto Filho', Daniel de Abreu Oliveira1', Alvaro de Assis Lopes Sobrinho',

Márcio Guilherme Rosa'1, Leonardo Fernades Aguiari', Cristiano Magalhäes Menezes ${ }^{1}$

1. Hospital Ortopédico/Lifecenter, Department of Orthopedics and Traumatology, Spine Surgery Group, Belo Horizonte, MG, Brazil.

\begin{abstract}
Objective: The objective of this study is to relate the use of intraoperative electromyography with surgical time, proper placement of screws, type of curve and time spent per screw in idiopathic scoliosis correction surgery in a group of surgeons from Belo Horizonte. This study used the database of protocol evaluation of patients operated in the service, and separately analyzed the results of motor and somatosensory potentials. Methods: Retrospective study of 80 patients undergoing surgery for correction of idiopathic scoliosis between December 2008 and January 2015. A single group of Belo Horizonte spine surgeons performed the intraoperative electromyographic (EMG) monitoring. EMG was performed with stimulation of pedicle screws in patients undergoing instrumentation with pedicle screws as fixation elements. Results: The sample consisted of $85 \%$ females (mean age 17 years) and $37.5 \%$ of cases had classification type 1 AN of Lenke. Of the total surgical cases, $60 \%$ had EMG changes. Of the total cases analyzed, $66.3 \%$ were true positives for the result. Conclusion: Intraoperative monitoring with EMG is a very important tool for the surgical treatment of patients with scoliosis undergoing instrumentation with pedicle screws. It enables to check if the screw is located on the correct path, helping to decrease the error rate and providing corrections to the surgical approach through a change of strategies. Moreover, it contributes to decrease the time to screw positioning and the total surgical time.
\end{abstract}

Keywords: Spine; Electromyography; Scoliosis; Pedicle screws.

\section{RESUMO}

Objetivo: O objetivo deste estudo é relacionar a utilização da eletromiografia intraoperatória com tempo cirúrgico, posicionamento dos parafusos, tipo de curva e tempo por parafuso em cirurgias de correção de escoliose idiopática, em um grupo de cirurgiões de Belo Horizonte. Este trabalho utilizou o banco de dados de avaliação do protocolo de pacientes operados no serviço, e analisou separadamente os resultados do potencial motor e somatossensorial. Métodos: Estudo retrospectivo de 80 pacientes submetidos a tratamento cirúrgico para correção de escoliose idiopática no período de dezembro de 2008 e janeiro de 2015. Foi realizada a monitorização eletromiográfica (EMG) intraoperatória por um único grupo de cirurgiões de coluna de Belo Horizonte. Foi realizada EMG com estimulação dos parafusos pediculares nos pacientes submetidos à instrumentação com parafusos pediculares como elementos de fixação. Resultados: A amostra foi constituída por 85\% sendo indivíduos do sexo feminino (média de idade de 17 anos) e 37,5\% dos casos tinham classificação do tipo 1AN de Lenke. Do total de casos cirúrgicos, 60\% apresentaram alteração EMG. Do casos analisados, 66,3\% eram verdadeiros positivos para o resultado. Conclusão: A monitorização intraoperatória com EMG é uma ferramenta importante para o tratamento cirúrgico de pacientes com escoliose submetidos à instrumentação com parafusos pediculares. É possível verificar se o parafuso está localizado no trajeto correto, contribuindo para diminuição do índice de erros e propiciando correções da abordagem cirúrgica, com a mudança de estratégias. Além disso, contribui diretamente para a redução de tempo de posicionamento do parafuso e do tempo cirúrgico total.

Descritores: Coluna vertebral; Eletromiografia; Escoliose; Parafusos pediculares.

\section{RESUMEN}

Objetivo: El objetivo de este estudio es relacionar el uso de la electromiografía intraoperatoria con el tiempo quirúrgico, la colocación de los tornillos, el tipo de curva y el tiempo por tornillo en la cirugía de corrección de la escoliosis idiopática en un grupo de cirujanos de Belo Horizonte. Este trabajo utilizó la base de datos de evaluación de protocolos de los pacientes operados en el senvicio y analizó los resultados de los potenciales motor y somatosensorial por separado. Métodos: Estudio retrospectivo de 80 pacientes que se sometieron a tratamiento quirúrgico para la corrección de la escoliosis idiopática entre diciembre de 2008 y enero de 2015. Un solo grupo de cirujanos de columna de Belo Horizonte realizó la monitorización electromiográfica (EMG) intraoperatoria. Se realizó EMG con la estimulación de los tornillos pediculares en pacientes sometidos a la instrumentación con tornillos pediculares como elementos de fijación. Resultados: La muestra consistió en 85\% de mujeres (edad media de 17 años) y el 37,5\% de Ios casos tenía clasificación del tipo 1AN de Lenke. Del total de los casos quirúrgicos, el 60\% tenía cambio EMG. De los casos analizados, el 66,3\% fueron verdaderos positivos para el resultado. Conclusión: La monitorización intraoperatoria con EMG es una herramienta importante para el tratamiento quirúrgico de los pacientes con escoliosis sometidos a la instrumentación con tornillos pediculares. Esto permite comprobar si el tornillo se encuentra en la trayectoria correcta, lo que ayuda a disminuir la tasa de errores y favorece correcciones del abordaje quirúrgico, con el cambio de las estrategias. Por otra parte, contribuye directamente a la reducción del tiempo de posicionamiento del tornillo y del tiempo quirúrgico total.

Descriptores: Columna vertebral; Electromiografía; Escoliosis; Tornillos pediculares. 


\section{INTRODUCTION}

Idiopathic scoliosis is described as a complex three-dimensional deformity of the trunk, with lateral deviation and rotation of the vertebral bodies standing out among the pathological components of the deformity. ${ }^{1}$

The pedicular screw fixation system is currently the gold standard for surgical correction of this pathology. ${ }^{2}$ However, there is a risk of neurological injury during screw placement and correction of the curve that, although rare, is catastrophic when it occurs. ${ }^{3}$

Thus, in order to prevent such injuries, principally during screw placement, surgeons use intraoperative myography, a very useful tool. This tool guides the surgeon during the procedure in real time, contributing to the proper and safe positioning of the pedicle screws.

The objective of this study is to correlate the use of intraoperative electromyography with surgical time, proper screw placement, curve type, and time per screw in corrective idiopathic surgeries performed by a group of surgeons in Belo Horizonte.

\section{MATERIALS AND METHODS}

This was a retrospective, observational, and analytical study, approved by the Institutional Review Board as protocol 50821715.9.0000.5126, of 80 patients who underwent surgical treatment for the correction of idiopathic scoliosis during the period from December, 2008 to January, 2015, of whom 85\% were female, with an average age of 17 years (with a minimum of six and a maximum of 34 years of age). In $37.5 \%$ of the cases, the curve presented was classified as Lenke idiopathic 1AN. Intraoperative electromyographical (EMG) monitoring was performed for all patients by a single group of surgeons in Belo Horizonte.

EMG changes occurred in $60.0 \%$ of the surgeries, of which $1.3 \%$ presented pre-procedure deficits and $3.75 \%$ presented postprocedure deficits. Of the total cases analyzed, $66.3 \%$ had true positive outcomes.

The indication for surgical treatment was made based on clinical and radiographic criteria in accordance with world literature. The screws were positioned via open posterior access with anatomical identification of the entry points and the positioning of screws for small fragments as position markers. Placement was confirmed by performing intraoperative anterior-posterior radiography and then replacement with permanent pedicle screws was performed.

The group had an exclusive neuromonitoring team consisting of a neurologist and a physiotherapist.

No patient received pre-anesthetic medication. Monitoring in the operating room consisted of electrocardioscopy, heart rate, peripheral arterial oxygen saturation, non-invasive blood pressure, and capnography.

Intravenous anesthesia was used in order to minimize interference in the EMG responses. Ventilation was maintained mechanically by volume or pressure.

Muscle relaxants were not used, except in patients with difficult endotracheal intubation, in which case short-acting curarizing drugs were used to facilitate the anesthetic procedure of endotracheal intubation.

The complete neurological examinations of all patients were reviewed after 24 hours, daily, and at discharge from the hospital.

EMG with stimulation of the pedicle screws was performed in all patients submitted to instrumentation with pedicle screws as fixation elements. A 16-channel neurophysiological analyzer (model Endeavor CR) was used to perform these procedures.

Transpedicular screw placement was monitored by EMG, with pickup via surface electrodes (model Spes Medica) positioned in muscles representative of the myotomes to be monitored for screw placement. (Table 1) Cathodic electrical stimulation was performed by a rod stimulator, also called needle-type anode, located in soft parts, with a stimulus at an intensity of 10 microamperes, duration of $0.2 \mathrm{~ms}$, and stimulus frequency of $3 \mathrm{~Hz}$. The response was considered to be changed when there was a muscle response following stimulation of the screw.
The result was based on the presence or absence of neurological changes, such as a post-operative deficit or change in the EMG. The result of the EMG monitoring was defined as the result recorded by the neuromonitoring system.

A negative result in the EMG monitoring was defined when the surgical maneuver did not cause a drop in amplitude below the warning threshold. The success of neuromonitoring in detecting neurological deficits caused by surgery can be expressed as values of false positive and false negative.

In order to describe the categorical variables of the study, absolute and relative frequencies were used, while the average, standard deviation, minimum, maximum, and quartiles were used to describe the quantitative variables.

To verify the associations between the categorical variables we used the chi-square test and Fisher's exact test, as necessary. The MannWhitney and Kruskal-Wallis tests were used to compare the quantitative variables with the categorical variables. For multiple comparisons, the Nemenyi test was used following the Kruskal-Wallis test.

The software used for analysis was R, version 3.0.3.

\section{RESULTS}

\section{Descriptive analysis}

In the descriptive analysis, according to Table 1, the categorical variables were described with absolute and relative frequency. The quantitative variables were described with the average, the standard deviation, the minimum, the maximum, and the $1^{\text {st }}, 2^{\text {nd }}$, and $3^{\text {rd }}$ quartiles.

The average time of duration of the surgical procedure was 320.76 minutes, with a standard deviation of 83.72 minutes, with a minimum of 161 and a maximum of 596 minutes, and an average of 18.84 screws per surgery, with a minimum of 12 an a maximum of 30 screws.

The average time per screw was 8.27 minutes, with a standard deviation of 2.43 minutes, with a minimum of 3.6 and a maximum of 17.8 minutes. The average percentage of accuracy among the surgeons of the group was $91.30 \%$, ranging from 69 to $100 \%$.

The average curve of the thoracic spine of the surgically treated patients was $52.80^{\circ}$, ranging from curves of $32^{\circ}$ to severe curves of $135^{\circ}$. The average curve of the lumbar spine was $47.40^{\circ}$, ranging from a minimum of $24^{\circ}$ to a maximum of $80^{\circ}$.

\section{Statistical analysis}

When screw positioning times were compared by type of curve, there was no difference in the distribution of screw time and types of curves.

Table 2 displays the comparisons of Percentage of Accuracy and the type of curve, none of which are statistically significant ( $p$-value $<0.05$ ), i.e.,

Table 1. Frequency of the categorical variables.

\begin{tabular}{c|c|c|c}
\hline \multicolumn{2}{c|}{ Variables } & N & $\%$ \\
\hline \multirow{4}{*}{ Sex } & Female & 68 & $85.0 \%$ \\
\cline { 2 - 4 } & Male & 12 & $15.0 \%$ \\
\hline \multirow{4}{*}{ Pathology } & Idiopathic Lenke 1AN & 30 & $37.5 \%$ \\
\cline { 2 - 4 } & Idiopathic Lenke 1BN & 6 & $7.5 \%$ \\
\cline { 2 - 4 } & Idiopathic Lenke 3CN & 9 & $11.25 \%$ \\
\cline { 2 - 4 } & Idiopathic Lenke 5CN & 11 & $13.75 \%$ \\
\cline { 2 - 4 } & Idiopathic Lenke 6CN & 10 & $12.5 \%$ \\
\cline { 2 - 4 } & Others & 14 & $17.5 \%$ \\
\hline \multirow{3}{*}{ EMG change } & No & 32 & $40.0 \%$ \\
\cline { 2 - 4 } & Yes & 48 & $60.0 \%$ \\
\hline \multirow{3}{*}{ Pre-Deficits } & With deficits & 1 & $1.3 \%$ \\
\cline { 2 - 4 } & Without deficits & 79 & $98.8 \%$ \\
\hline \multirow{2}{*}{ Post-Deficits } & With deficits & 3 & $3.75 \%$ \\
\cline { 2 - 4 } & Without deficits & 77 & $96.25 \%$ \\
\hline \multirow{2}{*}{ Results } & True negative & 27 & $33.8 \%$ \\
\cline { 2 - 4 } & True positive & 53 & $66.3 \%$ \\
\hline
\end{tabular}


there was no difference in the distribution of the Percentage of Accuracy when compared by hospital, surgeon, or pathology.

We observed no difference in the distribution of the occurrence of Pre-Deficits when compared by the results of "EMG FRISand "EMG"

Table 3 presents the comparison of the occurrence of Post-Deficits by the "EMG FR\S" and "EMG" variables. None of the comparisons is significant ( $p$-value $<0.05)$, i.e., there was no difference in the distribution of the occurrence of Post-Deficits when compared by the results of "EMG $F R \backslash S$ " and "EMG"

The following comparisons between the categorical variables of the Free-Running and Stimulated Electroneuromyographs can be noted as significant (Table 4 ):

In $58.3 \%$ of the men T6 to L4 and S2 electroneuromyography was verified, while in $52.9 \%$ of the women T6 to S2 electroneuromyography, these being significant associations ( $p$-value $=0.002$ ).

Among the results of the comparisons of the EMG FR\S and EMG Change variables, we confirmed that:

Free-running and Stimulated Electroneuromyography were true positive for $45.8 \%$ of the individuals in the T6 to L5 and S2 occurrence and true positive for $81.1 \%$ of the individuals in the T6 to S2 occurrence, reflecting a statistically significant difference ( $p$-value $=0.016)$.

$100 \%$ of the individuals with electroneuromyography (EMG) changes had true positive results, while only $15.6 \%$ of the individuals without these changes had true positive results, a statistically significant difference $(p$-value $=0.000)$.

Additionally, there was no difference in the distribution of the occurrence of Pre- and Post-Deficits when compared to the "EMG Change" results.

For the comparisons of the quantitative variables between EMG $F R \backslash S$, it should be noted that:

The percentage of accuracy was lower for the T6 to S2 EMG (0.89) as compared to the T6 to L5 and S2 EMG (1.00), and was the only significant comparison ( $p$-value $=0.035$ ).

Table 2. Comparison of the percent of accuracy and type of curve.

\begin{tabular}{|c|c|c|c|c|c|c|c|c|}
\hline Variables & $\begin{array}{l}\text { Percentage } \\
\text { of accuracy }\end{array}$ & $\mathbf{N}$ & Average & S.E. & $\begin{array}{c}1 s t \\
0\end{array}$ & 2ndo & 3rdo & $p$-value \\
\hline \multirow{6}{*}{ Pathology } & $\begin{array}{l}\text { Idiopathic } \\
\text { Lenke 1AN }\end{array}$ & 29 & 0.92 & 0.02 & 0.86 & 0.95 & 1.00 & \multirow{6}{*}{0.692} \\
\hline & $\begin{array}{l}\text { Idiopathic } \\
\text { Lenke 1BN }\end{array}$ & 6 & 0.88 & 0.04 & 0.78 & 0.91 & 0.94 & \\
\hline & $\begin{array}{l}\text { Idiopathic } \\
\text { Lenke 3CN }\end{array}$ & 8 & 0.91 & 0.04 & 0.83 & 0.98 & 1.00 & \\
\hline & $\begin{array}{l}\text { Idiopathic } \\
\text { Lenke 5CN }\end{array}$ & 11 & 0.94 & 0.02 & 0.90 & 0.98 & 1.00 & \\
\hline & $\begin{array}{l}\text { Idiopathic } \\
\text { Lenke } 6 \mathrm{CN}\end{array}$ & 10 & 0.91 & 0.02 & 0.87 & 0.91 & 1.00 & \\
\hline & Others & 13 & 0.89 & 0.03 & 0.83 & 0.88 & 0.96 & \\
\hline
\end{tabular}

Table 3. Comparison of the occurrence of post-deficits among the results of EMG FR $\backslash E$, EMG Changes.

\begin{tabular}{c|c|c|c|c|c|c}
\hline \multirow{2}{*}{ Variables } & \multicolumn{5}{|c|}{ Post-deficit } & \multirow{2}{*}{ p-value } \\
\cline { 2 - 6 } & \multicolumn{2}{|c|}{ Without deficit } & \multicolumn{2}{c|}{ With deficit } & & \\
\hline \multirow{4}{*}{ EMG FRIS } & T6 to L4 and S2 & 15 & $88.2 \%$ & 2 & $11.8 \%$ & \\
\cline { 2 - 6 } & T6 to L5 and S2 & 23 & $95.8 \%$ & 1 & $4.2 \%$ & \multirow{2}{*}{0.078} \\
\cline { 2 - 6 } & T6 to S2 & 37 & $100.0 \%$ & 0 & $0.0 \%$ & \\
\cline { 2 - 6 } & Total & 75 & $96.2 \%$ & 3 & $3.8 \%$ & \multirow{2}{*}{-} \\
\hline \multirow{3}{*}{ EMG Changes } & No & 28 & $90.3 \%$ & 3 & $9.7 \%$ & \multirow{2}{*}{0.059} \\
\cline { 2 - 6 } & Yes & 47 & $100.0 \%$ & 0 & $0.0 \%$ & \\
\cline { 2 - 6 } & Total & 75 & $96.2 \%$ & 3 & $3.8 \%$ & - \\
\hline
\end{tabular}

Table 4. Comparison of the EMG FR\E between pathology and sex.

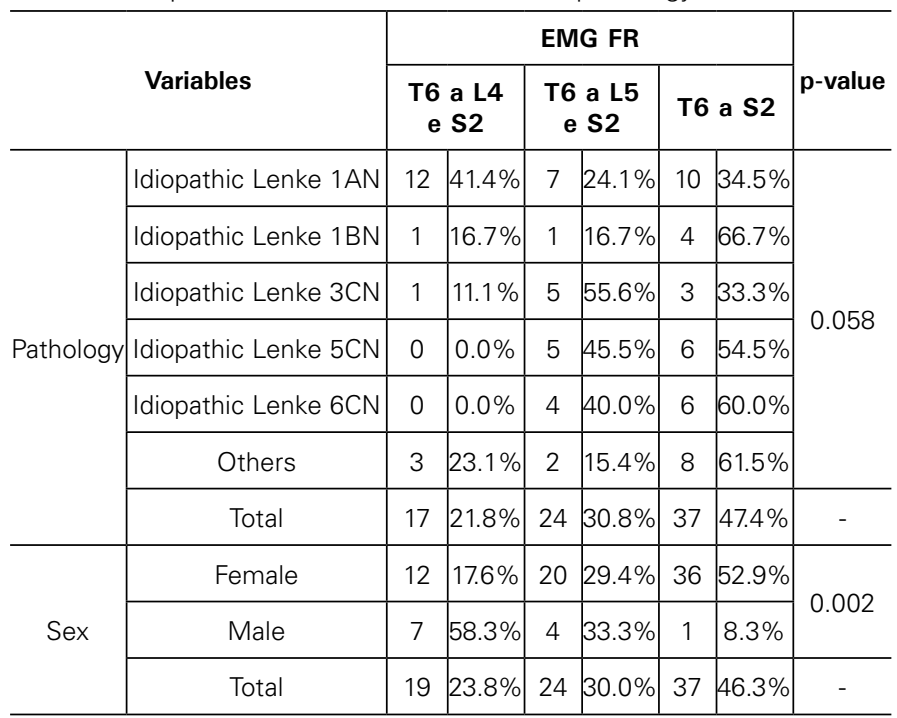

\section{DISCUSSION}

Postoperative radiculopathy is the most common complication from thoracolumbar surgery, especially in patients who have undergone segmental instrumentation, where the incidence may be greater than $10 \% .{ }^{4}$ Intraoperative neuromonitoring of the spine has become essential in deformity correction surgeries. ${ }^{5}$ However, the proper dissection of the anatomical references, including the facet joint and transverse processes, is of fundamental importance to the correct location of the point of entry of the screws and their proper placement. After the introduction of the screw placement guides, it is essential to palpate the path to check it, as well as the lateral, medial, upper, and lower walls and the bony base.

We chose stimulus with EMG as a reference during the instrumentation stages because it is even more sensitive than SSEP. ${ }^{6}$ Considering the time necessary to detect dysfunctions of the spinal neural elements, somatosensory evoked potentials reveal dysfunction approximately 11 minutes after the change in the somatosensory path occurs. ${ }^{7}$ This technique, however, does not guarantee accurate information in all cases. The responses can be easily influenced by various anesthetic agents, even when using advanced methods of stimulation. We stress the importance of the anesthetic protocol, care with hypotension and electrocautery, which can alter the response being monitored. As early as 1975, MacEwen et al. presented to the Scoliosis Research Society that neurological recovery is directly related to the speed of instrumental withdrawal. ${ }^{8}$

EMG is more sensitive than dermatomal SSEP in detecting radiculopathy and it can provide continuous information in real time about root function during the surgery. ${ }^{9}$ An increase in the frequency of the potential of the motor unit is sensitive and specific for an abrupt mechanical irritation and/or nerve root injury. ${ }^{10}$ Consequently, EMG monitoring can provide continuous feedback so that the surgeon can determine the possibility and location of a nerve root injury. ${ }^{11}$

The pedicle stimulation technique permits the monitoring and identification of compromised pedicles even before nerve root damage occurs. When the screws are correctly placed, cortical bone separates them from the nerve roots, ${ }^{12}$ functioning as a barrier of high impedance to the passage of the electrical current. ${ }^{13} \mathrm{~A}$ fracture of the pedicular wall breaks this barrier causing the corresponding myotomal muscle to respond with a stimulus of less intensity than when the pedicular wall is intact. A stimulus threshold less than 4-5 mA suggests perforation of the cortical bone by the transpedicular instrumentation. ${ }^{14}$

We confirmed that there were no false negatives with the use of Stimulated EMG. This response can occur with violation of the cortical bone, which does not necessarily mean that there was a violation of the nerve root, although the risk does exist. In these cases, replacement of the screws is recommended in accordance 
with the literature and the experience of the surgical team. A false negative can occur when there is no response. A false negative can occur in two ways: equipment failure at the time of surgery, which can be avoided by verifying all equipment, including the software, and a physiological false negative, which can include a situation in which the pedicle is fractured without EMG changes.

For effective monitoring, clear, continuous communication between the surgical team, the neurologist, and the anesthesiologist is important. ${ }^{15,16}$

This study considered any change in neuromonitoring to be a true positive and the information obtained by the examinations influenced the course of the surgery, in most cases causing the withdrawal and/or repositioning of the pedicle screws. This fact is supported by the greater surgical time and time per screw related to changes in the EMG.

\section{CONCLUSION}

Intraoperative monitoring with EMG is a very important tool for the surgical treatment of patients with scoliosis via pedicle screw instrumentation. Using this resource, it is possible to confirm the correct path, contributing to a decrease in the error rate and the number of post-arthrodesis re-surgeries, allowing changes in surgical strategy in addition to contributing directly to reductions in screw placement time and total surgical time. It should be noted that using electroneuromyography does not preclude the technical and anatomical knowledge required by the surgeon for the placement of the pedicle screws or for the determination of their length.

All the authors declare that there are no potential conflicts of interest regarding this article.

CONTRIBUTIONS OF THE AUTHORS: Each author made significant individual contributions to the development of the manuscript AAD and CMM were the main contributors to the writing of the manuscript. AAD, MAFJ, MGPD, RSF, MAPF, DAO, AALS, MGR, LFA, and CMM performed the surgeries and collected the clinical data. RABL was responsible for the intraoperative electromyography of all the patients who underwent surgery in the service and contributed to clinical data collection. AAD evaluated the statistical analysis data. AAD and CMM conducted the bibliographical research, the review of the manuscript, and they contributed to the intellectual concept of the study.

\section{REFERENCES}

1. Schimidt AC. Fundamental principles on treatment of scoliosis. AAOS Instr Course Lect. 1959;16:184.

2. Carlioz $\mathrm{H}$, Ouaknine M. Neurologic complications of surgery of the spine in children. Chirurgie. 1994-1995;120(11):26-30.

3. Cervellati S, Bettini N, Bianco T, Parisini P. Neurological complications in segmental spinal instrumentation: analysis of 750 patients. Eur Spine J. 1996;5(3):161-6.

4. Vogel LC, Lubicky JP. Neurologic and vascular complications of scoliosis surgery in patients with Ehlers-Danlos syndrome. A case report. Spine (Phila Pa 1976). 1996;21(21):2508-14.

5. Mittal S, Farmer JP, Poulin C, Silver K. Reliability of intraoperative electrophysiological monitoring in selective posterior rhizotomy. J Neurosurg. 2001;95(1):67-75.

6. Maguire J, Wallace S, Madiga R, Leppanen R, Draper V. Evaluation of intrapedicular screw position using intraoperative evoked electromyography. Spine (Phila Pa 1976). 1995;20(9):1068-74.

7. Holland NR. Intraoperative electromyography during thoracolumbar spinal surgery. Spine (Phila Pa 1976). 1998:23(17):1915-22

8. MacEwen GD, Bunnell WP, Sriram K. Acute neurological complications in the treatment of scoliosis. A report of the Scoliosis Research Society. J Bone Joint Surg Am. 1975;57(3):404-8.

9. Nuwer MR, Dawson EG, Carlson LG, Kanim LEA, Sherman JE. Somatosensory evoked potential spinal cord monitoring reduces neurological deficits after scoliosis sur- gery: results of a large multicenter survey. Electroencephalogr and Clin Neurophysiol. 1995:96(1):6-11.

10. Accadbled F, Henry P, de Gauzy JS, Cahuzac JP. Spinal cord monitoring in scoliosis surgery using an epidural electrode. Results of a prospective, consecutive series of 191 cases. Spine (Phila Pa 1976). 2006;31(22):2614-23.

11. Owen JH, Laschinger J, Bridwell K, Shimon S, Nielsen C, Dunlap J, et al. Sensitivity and specificity of somatosensory and neurogenic-motor evoked potentials in animals and humans. Spine (Phila Pa 1976). 1988;13(10):1111-8.

12. Hicks JM, Singla A, Shen FH, Arlet V. Complications of pedicle screw fixation in scoliosis surgery: a systematic review. Spine (Phila Pa 1976). 2010;35(11):E465-70.

13. Noordeen MH, Lee J, Gibbons CE, Taylor BA, Bentley G. Spinal cord monitoring in operations for neuromuscular scoliosis. J Bone Joint Surg Br. 1997:79(1):53-7.

14. Calancie B, Madsen P, Lebwohl N. Stimulus-evoked EMG monitoring during transpedicular lumbosacral spine instrumentation. Initial clinical results. Spine (Phila Pa 1976). 1994;19(24):2780-6.

15. Taniguchi M, Nadstawek J, Pechstein U, Schramm J. Total intravenous anesthesia for improvement of intraoperative monitoring of somatosensory evoked potentials during aneurysm surgery. Neurosurgery. 1992;31(5):891-7.

16. Kawaguchi M, Sakamoto T, Inoue $\mathrm{S}$, Kakimoto M, Furuya $\mathrm{H}$, Morimoto T, et al. Low dose propofol as a supplement to ketamine-based anesthesia during intraoperative monitoring of motor-evoked potentials. Spine (Phila Pa 1976). 2000;25(8):974-9. 